\title{
Computational Analysis of Wind Energy Input into Overhead Power Lines: Turbulence
}

\author{
Harry Payne ${ }^{1}$, Hassan Nouri ${ }^{2}$, and Rohitha Weerasinghe ${ }^{1}$ \\ ${ }^{1}$ University of the West of England \\ ${ }^{2}$ UWE Bristol
}

August 10, 2021

\begin{abstract}
Alternate shedding of vortices from the top and bottom of a conductor in a flow of wind causes Aeolian vibrations in overhead lines. Energy transfer to the conductors are calculated using the energy balance method. Simulation of wind power input into a harmonically oscillating cylinder by a turbulent flow is solved by numerical integration of the Naiver-Stokes equations using a numerical simulation tool. The results show that the assumption of lock-in phenomenon has oscillatory behaviour at lower amplitude to diameter (A/d) ratios for forced cylinder motion. Numerical results are in good agreement in the laminar case and k- $\omega$ SST turbulent case with measurements. The relationship between cylinder motion and vortex shedding is unsteady resulting in lower power transfer to the cylinder. The vortex shedding frequency oscillates with $10 \%$ turbulent intensity and length scales of $25 \mathrm{~mm}, 50 \mathrm{~mm}$ and $75 \mathrm{~mm}$.
\end{abstract}

\section{Hosted file}

Harry-Paper-revised-3.docx available at https://authorea.com/users/430087/articles/533627computational-analysis-of-wind-energy-input-into-overhead-power-lines-turbulence 